\title{
Interactive comment on "Climate benefits of proposed carbon dioxide mitigation strategies for international shipping and aviation" by Catherine C. Ivanovich et al.
}

\section{Anonymous Referee \#2}

Received and published: 3 May 2019

In this study, a simplified climate model is applied to analyze the impact of several $\mathrm{CO}_{2}$ mitigation scenarios for the international shipping and aviation sectors. Not only the impact of $\mathrm{CO}_{2}$, but also of other co-emitted short-lived compounds is considered and the resulting effects on near surface air temperature up to 2100 are quantified.

The study focuses on a very important topic in view of the 1.5 degree goal set by the Paris Agreement and the ways to achieve it. It is well structured, clearly written, and in my opinion fits well to the scope of ACP.

A major criticism is that the results section is quite short and mentions very few previous studies. I would recommend to extend Section 3, adding more details and more 
citations, in particular concerning the role of the short-lived species. These compounds can be very relevant for the two sectors discussed here, as shown by several previous studies (see suggestions below). Also the uncertainties of the adopted simplified climate model in simulating the effects of short-lived species can be large and should be discussed.

I find nevertheless the manuscript suitable for publication, after addressing the detailed comments and suggestions listed below.

\section{MAJOR COMMENTS:}

- in Sect. 2.1, scaling shipping $\mathrm{SO}_{2}$ emissions by a factor 7 to account for the IMO regulations in fuel sulfur content (FSC) only makes sense if the RCP8.5 dataset assumes a 3.5\% FSC for the global shipping fleet. Is this really the case? The 3.5\% cap was enforced in 2012, but it was $4.5 \%$ before and the RCPs scenarios start the projection in 2000. Moreover, according to the second IMO Study (Buhaug et al., 2009), the actual FSC in the global shipping fleet was on average $2.7 \%$ before the introduction of the IMO regulations. Therefore it could be that the FSC value assumed in RCP8.5 is lower than $3.5 \%$ and the scaling factor to get to $0.5 \%$ is lower than 7 . Please check this.

- end of Sect. 2.3: I understand that a full discussion of the model uncertainties is beyond the scope of this study, but I would at least briefly summarize which of them are the most significant for the results presented here.

- P8, L2: you may also want to compare with Lund et al. (Environ. Sci. Technol., 2012).

- P8, L16: there are a few studies simulating the aerosol indirect effect in low-sulfur shipping scenarios you may want to mention, for example Lauer et al. (Environ. Sci. Technol., 2009) and Righi et al. (Environ. Sci. Technol., 2011).

- P8, L26-27: the switch from cooling to warming is not evident in Fig. 2b. Does it occur before 2020? Please clarify.

- P8, L28-33: the issue of aviation effects of short-lived species should be discussed in 
more detail (see Lee et al., Atmos. Environ., 2010; or Grewe et al., Aerospace, 2018). There are several studies arguing for the effect of aviation soot on natural cirrus clouds (e.g., Penner et al., J. Geophys. Res., 2019) and some groups even argued for an effect on warm clouds (Gettelman and Chen, Geophys. Res. Lett., 2013; Righi et al., Atmos. Chem. Phys., 2013; Kapadia et al., Atmos. Chem. Phys., 2016). Can the simple climate model used here account for these effects?

Interactive

comment

- P8, L29: what is the mechanism behind the cooling effect from nitrogen oxide? This gas can lead to the formation of ozone, which has a warming effect, but it also reduces methane lifetime, resulting in a cooling. Are these mechanisms included in the model?

- P8, L31-33: this is confusing, if you include the indirect aerosol effects, then you do address the impacts of aviation on cloudiness. You probably mean contrails and contrail-induced cloudiness here; please clarify and also add a citation to support the last statement in this sentence (warming effect).

- end of Sect. 3.1: only one study is cited for comparison. It would be good to add more, possibly more recent, studies.

- Sect. 3.2: the role of short-lived pollutants in the aviation scenarios is not discussed at all. I understand that, unlike the shipping scenarios, the analyzed aviation scenarios do not distinguish between $\mathrm{CO}_{2}$ and non- $\mathrm{CO}_{2}$ species, but at least some qualitative considerations could be added here.

MINOR SUGGESTIONS / CORRECTIONS:

- P1, L14: please specify how much is this allowable warming.

- P1, L33: how does the time-frame affect the share of global $\mathrm{CO}_{2}$ emissions? Shouldn't it be rather given for a specific year?

- P3, L18: I would change the title of Sect. 2.1, to make more clear that the baseline scenario is discussed here. I would also suggest to make two subsections of 2.1 , to better separate aviation from shipping. The same would apply to 2.2. Another option 
would be to merge 2.1 and 2.2 in a single section on emissions, with two subsections for shipping and aviation, respectively.

- P3, L27: "hold that level constant", I guess you are referring to the growth rate which is held constant, but that could be misunderstood as the actual emissions. I would be more explicit: "hold that growth rate constant".

- P4, L5: the RCP acronym should be explained.

- P4, L11: what do you mean by "all-forcings" BAU scenario?

- P4, L29: there are more recent estimates, for example Burkhardt and Kärcher (Nature Clim. Change, 2011).

- P6, L24: please provide a reference for these relationships.

- P6, L26: please replace "gas" by "species" or "compound", since also aerosols are considered here.

- P7, L4: $2100-1765+1=336$ years (?)

- P11, L13: it might be worthwhile to cite Fuglestvedt et al. (Environ. Sci. Technol., 2009) in this context.

- P11, L14-16: since this is the main motivation behind this work, I would suggest putting this sentence also in the introduction.

- Figure 1: the acronym MMT should be explained. Also, this is a non-SI unit: I would use $\mathrm{Tg}$ or $\mathrm{Gg}$ instead.

- Figure $3 a$ is discussed before Figure $2 b$. You could think about grouping the plots by sector since this reflects the way they are presented in the text.

Printer-friendly version

- Figure 4: it is hard to distinguish the lines for the different scenarios, since very similar colors are used for them. 
Interactive comment on Atmos. Chem. Phys. Discuss., https://doi.org/10.5194/acp-2019-126, 2019.
ACPD

Interactive comment 